\title{
MIDAS
}

Museus e estudos interdisciplinares

$11 \mid 2020$

Dossier temático: "Perspetivas sobre o museu eclético"

\section{Para uma árvore genealógica museológica: o caso singular do Museu Machado de Castro}

For a museological "family tree": the singular case of Machado de Castro Museum

\section{Duarte Manuel Freitas}

\section{OpenEdition}

\section{Journals}

\section{Edição electrónica}

URL: http://journals.openedition.org/midas/2127

DOI: $10.4000 /$ midas. 2127

ISSN: 2182-9543

\section{Editora:}

Alice Semedo, Paulo Simões Rodrigues, Pedro Casaleiro, Raquel Henriques da Silva, Ana Carvalho

\section{Refêrencia eletrónica}

Duarte Manuel Freitas, « Para uma árvore genealógica museológica: o caso singular do Museu Machado de Castro », MIDAS [Online], 11 | 2020, posto online no dia 19 novembro 2020, consultado no dia 21 novembro 2020. URL : http://journals.openedition.org/midas/2127 ; DOI : https://doi.org/ $10.4000 /$ midas. 2127

\section{Este documento foi criado de forma automática no dia 21 novembro 2020.}

\section{cc) (†) ()}

Midas is licensed under a Creative Commons Attribution-NonCommercial-ShareAlike 3.0 International License 


\section{Para uma árvore genealógica museológica: o caso singular do Museu Machado de Castro}

For a museological "family tree": the singular case of Machado de Castro

Museum

Duarte Manuel Freitas

\section{NOTA DO EDITOR}

Artigo recebido a 12.02.2019

Aprovado para publicação a 15.03.2020

\section{I - In principio ${ }^{1}$}

$1 \quad \mathrm{O}$ ato de fundar um museu pressupõe uma vontade humana primordial de preservar determinados elementos patrimoniais que transmitem identidade, história/memória, formas de cultura (material ou imaterial) e "sentidos de pertença". Ao longo dos séculos, criaram-se (e também se improvisaram) contextos espaciais e temáticos com vista à exibição coerente de obras e valores que o coletivo, ou até um só indivíduo, entendeu preservar, gerando um cosmos específico para peças já de si descontextualizadas do locus matricial.

2 Nem todas as missões museológicas foram propriamente bem-sucedidas, perecendo, não raras vezes, da ausência do criador, da ultrapassagem do entusiasmo inicial, das impossibilidades do foro financeiro, dos desastres causados por fenómenos naturais ou pela própria "mão humana", não excluindo ainda a falta de apoios provindos da sociedade civil ou mesmo das entidades instituidoras. 
3 Se a lista dos projetos museológicos vencidos pelo tanatismo irreversível não deixa de ser longa, a história também demonstra que o fim de um museu poderá dar início a outro congénere, com missão similar ou até mesmo distinta, revisto, por exemplo, na passagem (de todo ou parte) do acervo para uma instituição recém-criada. Os próprios museus poderão, de igual modo, constituir-se como "progenitores" ou auxiliadores na criação de instituições de valências similares, a partir da transferência de parte do legado patrimonial (exposto ou depositado nas reservas) para um novo organismo cuja missão melhor o enquadre.

\section{II - Ecce homo}

4 Falar da museologia conimbricense que se encontra na génese do Museu Machado de Castro remete-nos, indubitavelmente, para o seu instituidor António Augusto Gonçalves (1848-1932), uma das personalidades mais marcantes da cidade de Coimbra entre os séculos XIX e XX, cuja interferência no âmbito da salvaguarda do património o eleva a referência a nível nacional. Noutra ocasião (Freitas 2016) já cumprimos o objetivo estudá-lo de forma mais aprofundada, epitetando-o, inclusivamente, de "homem dos sete ofícios". Pretende-se, neste contexto, um exercício de óbvia sintetização, listando as áreas de atuação mais relevantes:

- Arte: dominou diversas disciplinas artísticas - pintura, desenho, escultura, cenografia, cerâmica, gravação, fotografia e serralharia -, entre as quais se destaca, pela qualidade do traço, o desenho de registo histórico, conquanto a sua relação com o produto final nem sempre tenha sido pacífica, levando-o a repudiar e destruir algumas das suas produções, sobretudo as de caráter pictórico;

- Arqueologia: integrou, nos finais do século XIX e princípios da centúria seguinte, importantes campanhas de escavações em Conimbriga e no Castelo de Montemor-o-Velho. Saliente-se, ainda neste âmbito, a sua capacidade de interpretação de estruturas arqueológicas, ao ser o primeiro a avançar com uma atribuição do período do domínio romano às galerias que sustentam o antigo paço episcopal de Coimbra, sendo este um facto que muitos dos especialistas da história de Aeminium atribuem, de forma errónea, à capacidade analítica de Vergílio Correia;

- Restauro arquitetónico: planificou diversas intervenções em monumentos da cidade, destacando-se o restauro do claustro de Celas - detentor dos conhecidos capitéis góticos da universidade dionisina -, a adaptação do colégio de São Tomás a residência do conde do Ameal, a passagem a espaços museológicos do paço episcopal e da igreja de São João de Almedina, bem como a reestruturação da Sé Velha - iniciada em 1893 e sob o patrocínio financeiro da rainha D. Amélia -, numa pretensão assente no enaltecimento da sua traça românica;

- Jornalismo: foi membro interveniente no espaço público conimbricense através da participação de diversos periódicos, desde o ano de 1872 (data em que fundou o jornal literário Zephiro) até ao seu falecimento. Redigiu, ao longo de 60 anos, mais de 500 artigos e crónicas jornalísticas, assinadas em nome próprio ou em pseudónimo, incidindo, em outros conteúdos temáticos, na proteção e salvaguarda do património nacional e instigando, com seu aguçado sentido crítico e escrita direta, várias polémicas com membros da elite intelectual portuguesa de todo o espectro político/ideológico;

- Política: numa entrevista ao Diário de Lisboa, de 22 de julho de 1921, Gonçalves elabora uma espécie autorretrato de matiz ideológico: 
[o meu pai] tinha muita habilidade. Era muito sério. Conservador e temente a Deus. Eu fiz-me no ódio às mentiras da igreja, aos seus crimes da Inquisição e fui Republicano. Meu pai teve doze filhos. Trabalhou e educou-os na moral. É que eu tenho uma moral que às vezes não parece deste tempo... (Araújo 1921, 3)

Como republicano de "primeira água", ocupou cargos de relevância na edilidade conimbricense, em 1887 como vereador e a partir de 1911 como primeiro presidente da municipalidade, após a revolução de outubro;

- Museologia: participação ativa em vários projetos museológicos da cidade do Mondego, fundando o Museu Municipal de Arte e Indústrias (1889) e o Museu Machado de Castro (1911), interferindo ainda, como conservador, no Museu do Instituto de Coimbra (a partir de 1895) e como inventariante no Museu de Arte Sacra/Tesouro da Sé de Coimbra (1911);

- Pedagogia: para além de ministrar aulas particulares de desenho na sua residência (na Rua dos Coutinhos), lecionou em coletividades de âmbito operário, em horário pós-laboral (Associação de Artistas de Coimbra, a partir de 1868 e Escola Livre das Artes do Desenho, a partir de 1878), em diferentes instituições de ensino (Colégio Académico, a Escola Académica, o Colégio dos Órfãos, o Seminário Episcopal, Escola Industrial Brotero) e, a nível superior, na Universidade de Coimbra, nas faculdades de Matemática e Filosofia e, mais tarde, já em período republicano, na Faculdade de Ciências.

5 Como cidadão atento às visíveis e constantes depredações do património históricoartístico, Gonçalves não deixou de criticar a incúria dos organismos públicos e o próprio Estado português, pela ausência de meios de proteção e de salvaguarda, como demonstra nas palavras que se seguem:

Depois de [18]34, os conventos das extintas ordens monásticas foram abandonados à avidez da exploração e do saque. Na perturbação produzida pela imprevista audacia do famoso decreto, não foram tomadas medidas de precaução, que resguardassem os bens mobiliários, que ficavam patentes às insolencias da rapacidade de grandes e pequenos. [...] E assim continuou por largos anos o desbarato irreprimido! (Gonçalves 1921, 2)

A sua voz crítica manteve-se inalterada mesmo durante a vigência política dos "seus", não se esquivando a reportar atos de desvio de espécimes artísticos, ocorridos sob a ordem republicana:

Uma desgraça! Quando veio a República, fui ter com o Afonso [Costa] e pedi-lhe para ele evitar que se repetissem os atentados e roubos de 1834. Pois foi muito pior, ainda que sem ser por culpa dele. Um saque perfeito, aqui por esta região. Nas Ursulinas não escapou nada, nada! Iam as coisas, não se sabe para onde, às carroçadas! [...] Sabe-se lá! Nem os paramentos ricos escaparam, ainda que eu suponha que muitos foram roubados pelos próprios padres para várias igrejas, antes que outros os roubassem. Felizmente, que não foi assim em toda a parte. (Araújo 1921, 3)

7 A matriz museológica gonçalvina conjugou-se em diversas vertentes e está de acordo com o seu perfil multifacetado e o profundo conhecimento da conjuntura pedagógica e artística desenvolvida em torno dos museus de arte industrial, num conceito nascido a partir da primeira grande exposição internacional, realizada em Hyde Park (Londres) no ano de 1851, e disseminado por vários países da Europa e pelos Estados Unidos da América. A fundação de espaços museológicos dedicados às artes aplicadas à indústria contendo, no seu âmago, escolas de desenho industrial anexas - almejaram a evolução e aperfeiçoamento profissional das classes operárias, sendo este o princípio onde assentou a crença pedagógica de Gonçalves e de outros ilustres contemporâneos, como 
por exemplo o seu amigo Joaquim de Vasconcelos, organizador do Museu Comercial e Industrial do Porto (1883).

8 A própria idealização e fundação, em 1878, da Escola Livre das Artes do Desenho espelha tais conceções gonçalvinas, expressas no primeiro artigo dos seus estatutos, pretendendo-se, com este coletivo, a

[...] propagação do estudo do desenho nas suas variadissimas applicações ás artes, artes industriaes e industrias fabris [...] [e a] [...] impulsão de todos os meios que possam favorecer em Coimbra, e mormente na classe operaria, o desenvolvimento do gosto, aperfeiçoamento das manufacturas e intelligencia das obras d'arte.

(Estatutos... 1880, art. ․ 1)

9 Nas instalações sitas na Torre de Almedina, em horário noturno, o professor de desenho criou uma espécie de "irmandade artística", cuja aplicabilidade dos ensinamentos não deixou de ser apreciada pelos seus contemporâneos, ao formar uma vasta lista de discípulos, alguns deles com elevada projeção nacional, como foram João Machado (canteiro e escultor), Costa Mota (escultor), Lourenço Chaves de Almeida (serralheiro), Jorge Colaço (azulejaria), Benjamim Ventura (trabalhos em madeira) e Fausto Gonçalves (pintor).

10 Ao êxito inicial da Escola Livre das Artes do Desenho, e de acordo com um desejo já impresso nos seus estatutos (art.․ 2.) ), o projeto de Gonçalves almejou a conceção de uma vertente museológica que permitisse aliar a arte às indústrias e, ao mesmo tempo, servir de reservatório protetor dos espécimes artísticos conimbricenses de antanho. Projetava-se, assim, o que podemos considerar o primeiro antepassado da arbor generationis do Museu Machado de Castro.

\section{III - Avorum}

A passagem de António Augusto Gonçalves pela vereação municipal, a partir dos inícios de 1887, originou a oportunidade de planificação e abertura de uma nova instituição museológica conimbricense, cuja tutela ficou sob a responsabilidade do executivo camarário. A proposta foi apresentada, pelo próprio Gonçalves, a 17 de março do referido ano, definindo-se a sua nomeação como conservador, quais as peças a expor e a fixação da estrutura conceitual, em coerência com o arquétipo do desenvolvimento das artes industriais. Assim, o Museu Municipal de Arte e Indústrias registou, no seu compromisso estatutário, a conjugação de dois quadros temáticos distintos: uma secção histórica,

[...] destinada a activar no espirito publico o gosto e sentimento da arte; a oferecer documentos uteis á propagação d'esta ordens de estudos; e ao mesmo tempo a elucidar e instruir a intelligencia dos artifices pela influencia da liç̧ão intuitiva de recommendaveis exemplares de trabalho antigo [...]; e uma seç̧ão de indústria moderna, que pretendia [...] evidenciar a aptidão, capacidade produtiva e recursos commerciaes da grande e pequena industria e industrias caseiras do districto, tornando conhecidos, em favor dos interesses do fabricante e do consumidor que possam ser aproveitados para o seu maior desenvolvimento mercantil. (BMC, espólio AAG, 1887, pasta B2)

A planificação do novo organismo museológico estendeu-se até aos finais de 1889. Abriu portas no dia 15 de dezembro, nos corredores norte e poente do claustro do silêncio do antigo mosteiro de Santa Cruz de Coimbra, sustentado, para além de peças da posse da autarquia, por espécies depositados em regime de empréstimo. Pretendia-se que a 
coleção exposta fosse, de igual modo, formada por «[...] productos originaes e reproducções, em modelação, imitações, desenhos, gravuras e photographias de obras d'arte ou arte industrial antiga, principalmente nacional» (BMC, espólio AAG, 1887, pasta B2).

Os tempos iniciais foram conturbados e manifestamente efémeros, encerrando em definitivo em março de 1890, com somente 14 dias de abertura ao público. As causas subjacentes ao fenecimento deste projeto encontram-se nas evidentes divergências entre Gonçalves, enquanto conservador, e o novo executivo camarário, vigente desde 2 de janeiro de 1890 e sob a liderança de Manuel da Costa Alemão, cujas ações evidenciam pouca vontade em consolidar uma instituição museológica ainda imberbe. Sete anos mais tarde, em 1897, o Instituto de Coimbra solicitou, à edilidade, a cedência do espólio para o espaço museológico da agremiação, obtendo tal missiva total anuência já no segundo semestre do referido ano, dissolvendo-se, desde modo, as tentativas de reabilitação do Museu Municipal de Arte e Indústrias (A. 1896, 1-2; Zebedeu 1917, 1).

o pedido efetuado pela citada comunidade científica, constituída por lentes, discentes e antigos alunos da academia coimbrã, deteve óbvia interferência de António Augusto Gonçalves, uma vez que, desde novembro de 1894, se encontrava no ativo como conservador no Museu do Instituto de Coimbra, com instalações sitas em duas salas do antigo colégio de São Paulo Eremita.

15 A origem deste espaço museológico remete-se para o ano de 1873, fruto da conceção de Aires dos Campos e de Augusto Filipe Simões, com o intuito de acondicionar as peças exumadas nas campanhas arqueológicas da agremiação - destacando-se o elevado número de artefactos proveniente das ruínas de Conimbriga -, a que se juntaram peças depositadas pelos sócios e outras vindas das instituições religiosas desamortizadas ou em pleno processo de desamortização (Catalogo... 1883 e 1887).

Enquanto conservador de um museu com uma missão científica clara, com grande incidência sobre os espécimes arqueológicos - bem longe da lógica inerente às artes industriais -, os préstimos de Gonçalves no Museu do Instituto de Coimbra passaram inicialmente por uma remodelação de monta no discurso expositivo, como explicam as palavras do contemporâneo Mendes dos Remédios, salientando que o espaço museológico, de

[...] pobre e abandonado, [...] massa tôsca e informe, começa a surgir uma forma elegante definida, vivaz e radiante. Transformou-se primeiro o local. Não mais cheiro de coisas húmidas e carcomidas. Luz e côr. Janelas amplas. Claridade na atmosfera. E o meio mudou tudo. As figuras tomaram atitudes. Os pequenos objectos vincaram feições. (Remédios 1927, 373)

Com nova reabertura, a 26 de abril de 1896, modificou-se a nomenclatura, passando a intitular-se de Museu de Antiguidades do Instituto de Coimbra, dada a equiparação evidente entre o espólio arqueológico e o artístico. Gonçalves participou ativamente numa nova remodelação espacial, já em 1911, revista no aumento de duas para cinco salas de exposição. Ainda assim, o espaço apresentou-se, no catálogo, como exíguo para o total de acervo a expor, colocando em causa a continuidade do museu no antigo colégio de São Paulo Eremita (Museu de Antiguidades... 1911, 3).

Como teremos oportunidade de explicar mais adiante, no mês de maio do mesmo ano definiram-se as bases concetuais do Museu Machado de Castro, compreendido, pela referida agremiação e por nichos da sociedade, como uma espécie de polo salvífico do património cultural conimbricense. A integração total do acervo do espaço museológico 
do Instituto de Coimbra na instituição recém-criada obteve a anuência por parte dos seus sócios, no dia 8 de agosto de 1912, originando, deste modo, o encerramento de uma instituição com quase 40 anos de existência.

Nas proximidades do colégio de São Paulo Eremita, mais propriamente nos espaços anexos à Sé Nova de Coimbra, instalou-se, em 1883, um museu de arte sacra - também conhecido por Tesouro da Sé -, a partir da iniciativa do bispo-conde D. Manuel Correia de Bastos Pina, cujo impulso fundacional passou, inicialmente, pela separação das alfaias mais importantes pertencentes ao Cabido para marcarem presença, em Lisboa, na Exposição Retrospetiva de Arte Ornamental Portuguesa e Espanhola (1882). Após a vinda do acervo da capital, e com o apoio inicial de Augusto Filipe Simões, o prelado instalou o novo espaço museológico que, paulatinamente, se expandiu por outras salas, dada a necessidade de incorporar o espólio provindo das casas femininas alvo de extinção e desamortização (Gomes 1914, 1).

Os trabalhos de inventário e edição do respetivo catálogo foram levados a cabo por António Augusto Gonçalves e Eugénio de Castro, com a publicação a sair já em pleno contexto republicano, no mês de fevereiro de 1911 (Gonçalves e Castro 1911) dois meses antes da promulgação da Lei da Separação do Estado das Igrejas (Decreto com força de Lei 20-04-1911). o pendor laicizante do regime publicano, presente no citado diploma, não deixa de interferir na tutela do espaço museológico, uma vez que procedeu à sua nacionalização, embora ressalve a permanência do prelado conimbricense no seu comando. Tal alínea indicia, em nosso entender, uma possível influência de António Augusto Gonçalves enquanto participante no longo processo de redação do referido diploma legislativo, pretendendo manter, sob a órbita do bispo-conde - de quem era próximo -, o acervo acautelado no referido espaço museológico e pôr fim a possíveis tentativas de separação/desagregação das coleções e ida para outras latitudes.

Em maio do referido ano, com a instituição oficial do Museu Machado de Castro (Decreto de 26-05-1911), o espaço museológico da Sé surge anexado à nova instituição, mantendo, contudo, a premissa, anteriormente consagrada, da direção se manter na pessoa de D. Manuel Correia de Bastos Pina, o que ocorreu, sem percalços significativos, até ao seu falecimento, a 19 de novembro de 1913.

\section{IV - Nativitate}

Entremos, por ora, no ato fundador do Museu Machado de Castro. A implantação da República deu a António Augusto Gonçalves a oportunidade ideal de colocar em práticas as suas conceções museológicas e agregar, numa só instituição tutelada pelo Estado, o património artístico disperso por outros espaços, acautelando-o em melhores condições de exposição e de salvaguarda. Esta ambição já se encontra espelhada numa carta aberta ao governo, datada de 30 de dezembro de 1910, assinada por membros de três organizações influentes na cidade - a Sociedade de Defesa e Propaganda de Coimbra, o Instituto de Coimbra e a Escola Livre das Artes do Desenho - entre os quais se inclui o próprio Gonçalves, onde se firma o compromisso com a preservação dos elementos patrimoniais através dos museus, apontando ainda que os futuros compromissos museológicos conimbricenses deverão partir do «[...] aproveitamento de algum estabelecimento que porventura o governo tenha em mente supprimir, ou pela modificação judiciosa do projecto de algum edifício em construção» (BMC, espólio AAG, 1910, pasta C2). 
ditames impressos na referida missiva encontram-se espelhados na fundação do próprio Museu Machado de Castro, pelo decreto de 26 de maio de 1911, numa produção legislativa republicana que almejou a reforma dos serviços artísticos e arqueológicos do país. No artigo 39. - redigido pelo próprio Gonçalves, como demonstra a correspondência que trocou com José de Figueiredo (Serra 2002, 137-139) - salienta-se a criação e missão do novo espaço museológico nos seguintes termos:

Com a designação de Museu Machado de Castro, é criada na segunda circunscrição um Museu Geral de Arte Geral, organizado principalmente no intuito de offerecer ao estudo público collecções e exemplares de evolução da história do trabalho nacional; e que será ampliado com uma secção de artefactos modernos, destinada à educação do gosto publico e à aprendizagem das classes operárias. (Decreto de 26-05-1911)

Em termos da nomenclatura adotada, constata-se a aplicação, à nova instituição, do nome do grande escultor régio dos finais do século XVIII e princípios da centúria seguinte, conquanto tal decisão não espelhasse, de todo, um programa museológico em torno das suas obras, dado que estas não se encontravam - e ainda hoje não se encontram - depositadas em Coimbra. Para além de conimbricense ilustre, o nome de Machado de Castro foi agregado ao novo organismo estatal pela sua importância, expressa inclusivamente no preâmbulo da lei, como defensor da pedagogia artística, como é visível nos escritos de seu punho.

O caráter didático do próprio artigo fundacional demonstra a aplicação efetiva das conceções gonçalvinas, assentes numa museologia para o desenvolvimento das artes industriais, já evidenciada nas missões anteriores instituídas por este, quer na Escola Livre das Artes do Desenho, quer no então extinto Museu Municipal de Arte e Indústrias, onde, neste último, as analogias são evidentes, numa concordância expositiva entre a arte antiga e os artefactos modernos como instrumentos de aprendizagem das classes operárias.

Entre a criação, no papel, do espaço museológico até à abertura de portas, ocorrida no dia 11 de outubro de 1913, foi necessário ultrapassar vários problemas subjacentes à recolha do acervo a expor, à procura de uma estrutura arquitetónica e a consequente aplicação de obras de beneficiação. 0 paço episcopal - nas proximidades da Sé Nova e das dependências do Tesouro da Sé - não deixou de ser visto, por Gonçalves, como o local ideal para a referida instalação, conquanto permanecesse ocupado pelo próprio prelado da diocese.

O processo de desamortização do edifício, e entrega para a alçada pública, foi deveras complexo e acarretou alguma polémica, com Gonçalves a aproveitar um extemporâneo pedido de renúncia do bispo-conde ao cargo que então ocupava - a que se seguiu uma partida para a Carregosa, de onde era natural - para oficializar, enquanto presidente do executivo camarário, o pedido de cedência do palácio episcopal, a 6 de dezembro de 1911. No ano seguinte, a 10 de fevereiro, a resposta governamental foi positiva, com o município a encarregar-se do arrendamento anual do paço pela quantia de $400 \$ 000$ réis (fig. 1). 


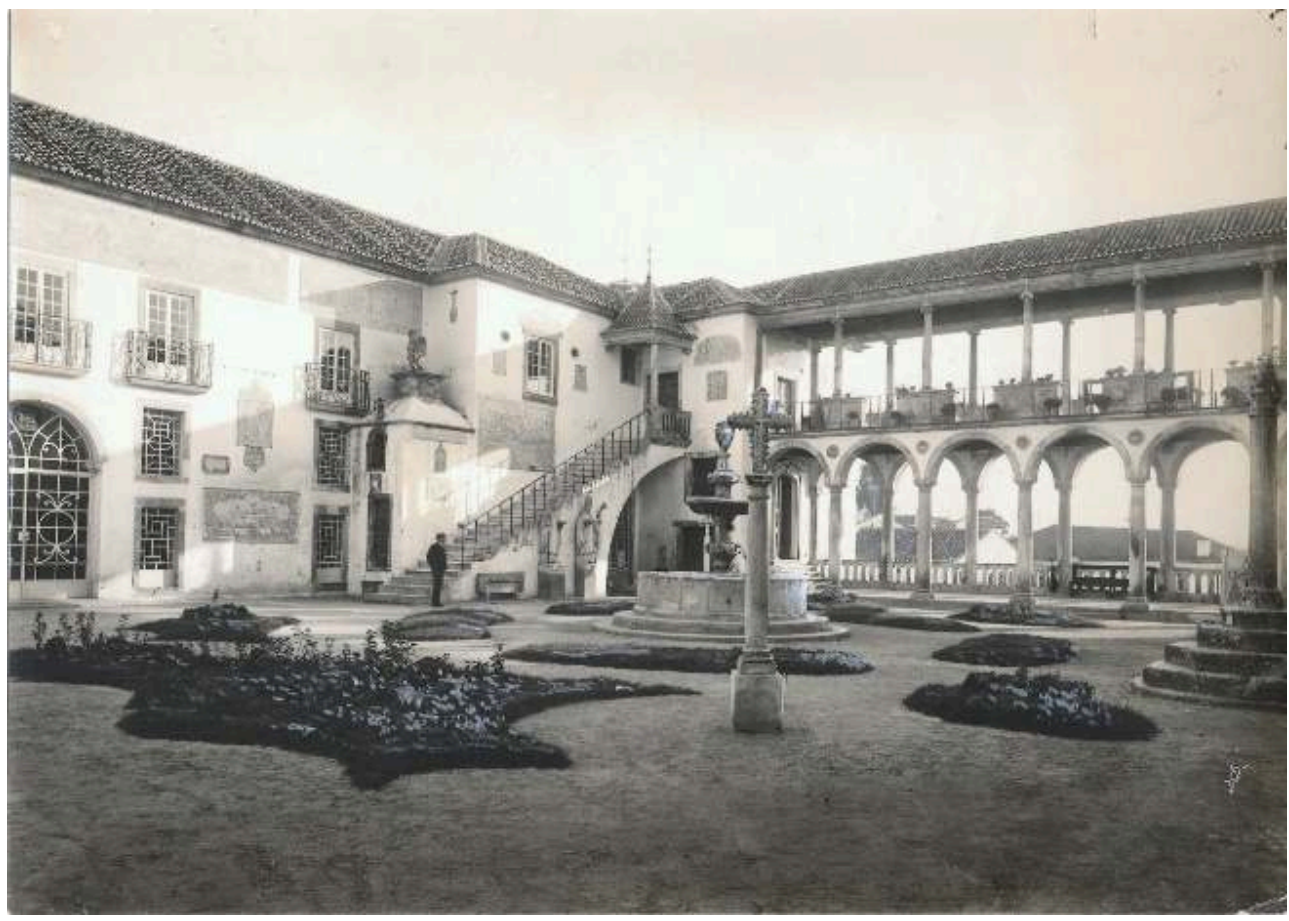

Fig. 1 - Pátio principal do Museu Machado de Castro. Década de 1920

(c) Arquivo Museu Nacional de Machado de Castro. Autor não identificado

Se tivermos em atenção à missão estabelecida para organismo como garante de uma museologia aplicada às artes industriais, tal como pretendeu o seu fundador e primeiro diretor, constata-se que, na prática, a realidade suplantou a idealização inicial do projeto, ao criar-se, sobretudo, um museu de belas-artes, com evidente domínio da escultura em pedra.

O objetivo de conceber uma instituição formadora da classe operária, onde os pupilos de coletividades educativas de base profissional - como a Escola Livre das Artes do Desenho ou a Escola Industrial Brotero - pudessem retirar os devidos ensinamentos não passou de uma quimera desejada por Gonçalves e os esforços diversos para que tal acontecesse resultaram em apresentações esparsas de obras realizadas por artistas e artífices no ativo, dispondo-as ao pé das peças antigas que lhe serviram de inspiração, como foi o caso ocorrido com o ferreiro Lourenço Chaves de Almeida, em maio de 1920 (Almeida 2007, 92-93).

30 Numa espécie de testamento museológico, António Augusto Gonçalves, no final da sua vida, regista, por escrito, um exame de consciência onde a frustração pelo resultado do que fez é por demais evidente, acima de tudo por não ter conseguido estruturar um polo formador das artes ligadas à indústria:

O Museu Machado de Castro é certo que tem prestado elucidações e paradigmas a marceneiros e entalhadores, etc., mas está longe de ser aproveitado pelos operários, mesmo em relatividade comparativa com o de Cluny e outros. E faz pena o pensar como seriam fecundadas [sic] as apreciáveis qualidades nativas do operariado português, se fossem aquecidas pela instrução técnica e pela educação integral das modernas Universidade do trabalho de Charlerroy, na Bélgica, por exemplo [...]. Chegado ao termo da jornada, depois de desenganos e perfidias de birbantes despresiveis, sínto que malbaratei o meu tempo, e o meu interesse, inutilmente e sem vantagem para a boa causa que julgava missionar e servir! Reconheço que desperdicei a vida a pensar em utopias e inepcias, com a leviandade de quem erra 
uma operação de aritmética! Anos consecutivos de cuidados e fadigas absolutamente gratuitas! Sem remuneração, abnegadamente liberto de calculos de ambições futuras, ou vislumbrados premios compensadores!... Para que tantas canceiras e contrariedades?... Se ninguem aproveitou com isso!?... (Gonçalves 1929, 1)

\section{V - Semina} no cargo de diretor do Museu Machado de Castro, desejou, logo no início do seu consolado à frente da instituição (a partir de 1929), incutir-lhe uma nova missão onde a arqueologia estivesse colocada em primeiro plano e de acordo com a sua formação científica. Numa resposta direta à pergunta "como se faz um museu?", dada através de um artigo publicado, no Diário de Coimbra, em 1935, enalteceu o seguinte:

[...] estabelecendo um plano e executando-o, criando as secções indispensáveis, não deixando perder elementos, vigiando os desaterros e as reconstruções, de modo a recolher tudo quanto é antigo, tudo quanto vai levar às colecções, o claro-escuro das cousas que morreram... e que perduram. (Correia 1935, 1)

o próprio Museu Machado de Castro beneficiou com a sua presença enquanto arqueólogo, conseguindo uma importante valorização da estrutura arquitetónica ocorrida a partir de sondagens, prospeções e escavações, que permitiram encontrar vestígios de outras edificações que a terra escondeu e que as constantes reutilizações ocultaram, colocando-as, inclusive, in situ, ao longo do discurso expositivo (fig. 2).

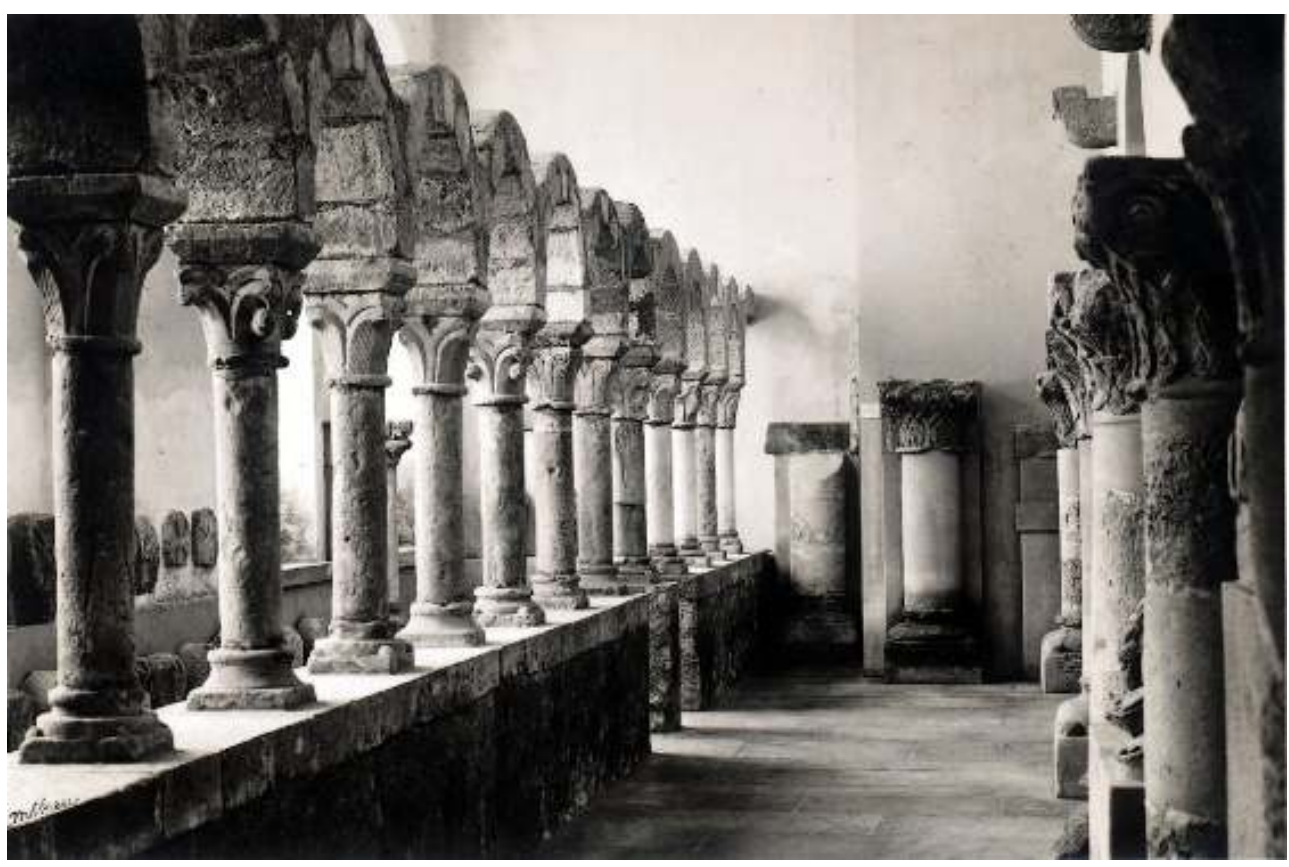

Fig. 2 - Pormenor do discurso expositivo da galeria românica do Museu Machado de Castro, com o claustro pré-românico da Igreja de São João de Almedina disposto in situ. Início da década de 1940

(c) Arquivo Museu Nacional de Machado de Castro. Autor não identificado

Além do espaço museológico conimbricense, o seu legado nos museus portugueses estende-se, de igual modo, a Condeixa, através das campanhas arqueológicas efetuadas em Conimbriga que permitiram um maior conhecimento sobre o célebre oppidum. Segundo o cónego António Nogueira Gonçalves, foi em Conimbriga que Vergílio Correia 
«[...] colocou essencialmente a sua alma, o seu tempo e, diga-se também, bastante das suas modestas receitas [...]» (Gonçalves 1971, 37), ao comandar, com a anuência da Direção Geral de Edifícios e Monumentos Nacionais, várias campanhas de escavação e prospeção na estância arqueológica que permitiram o "levantar do chão" de novos vestígios do período do domínio romano.

No seu entender as potencialidades das ruínas romanas não poderiam se quedar, somente, por uma simples visita à instância. Seria, de igual modo, necessária a criação de um espaço interpretativo anexo, onde tudo se contextualizasse, trazendo para si todas as peças pertencentes ao oppidum que se encontravam expostas na sala romana do Museu Machado de Castro. Atenda-se ao que referiu sobre este assunto já em 1936:

Para que esta obra se perpetue são indispensáveis a fundação de um museu, anexo às ruínas, projecto que a direcção dos monumentos acarinha; e a criação de uma comissão de iniciativa e turismo em Condeixa, a qual se justifica plenamente quer pela importância turística, cada vez maior, da região, quer pela existência na risonha vila de um grupo de pessoas activas e dedicadas à sua terra, capazes de independentemente de subordinações centralistas, executarem um programa de obras em benefício dos habitantes, e do país em geral. Esperemos. (Correia 1936, 1)

Demonstrando conhecer o contexto museológico europeu, no que à arqueologia e à interpretação in situ de ruínas dizia respeito, no início de 1940 voltou ao assunto nos seguintes termos:

A obra magnífica da restauração de Conímbriga perpetuar-se-ia pela construção de um edifício para museu, que a semelhança do que sucede em todos os centros arqueológicos de valor estrangeiros, recolheria para lição de amadores e investigação de especializados, as peças de mobiliário que completam o conhecimento e civilização que tão exuberante e superiormente ficou documentada em Condeixa-a-Velha. (Correia 1940b, 1)

Com o falecimento prematuro e inesperado, em 1944, do "D. Quixote de Conimbriga" como lhe chamou Miguel Torga (1999) - o seu desejo não feneceu, obtendo concretização efetiva somente em 1962, com a inauguração do Museu Monográfico de Conímbriga, num edifício projetado, com todos os preceitos modernos da arquitetura museológica da época, pelo arquiteto Luís Amoroso Lopes da Direção Geral de Edifícios e Monumentos Nacionais (Coelho 2016, 35-47).

Os artefactos até à época exumados nas referidas ruínas passaram da guarda do Museu Machado de Castro para o novo espaço museológico (fig. 3), que deteve como diretor J. M. Bairrão Oleiro (1923-2000), docente universitário e antigo conservador responsável pelo inventário e catalogação das coleções de Arqueologia no organismo museístico situado na Alta de Coimbra (AMNMC, CE, 1952; AMNMC, CR, 1962). 


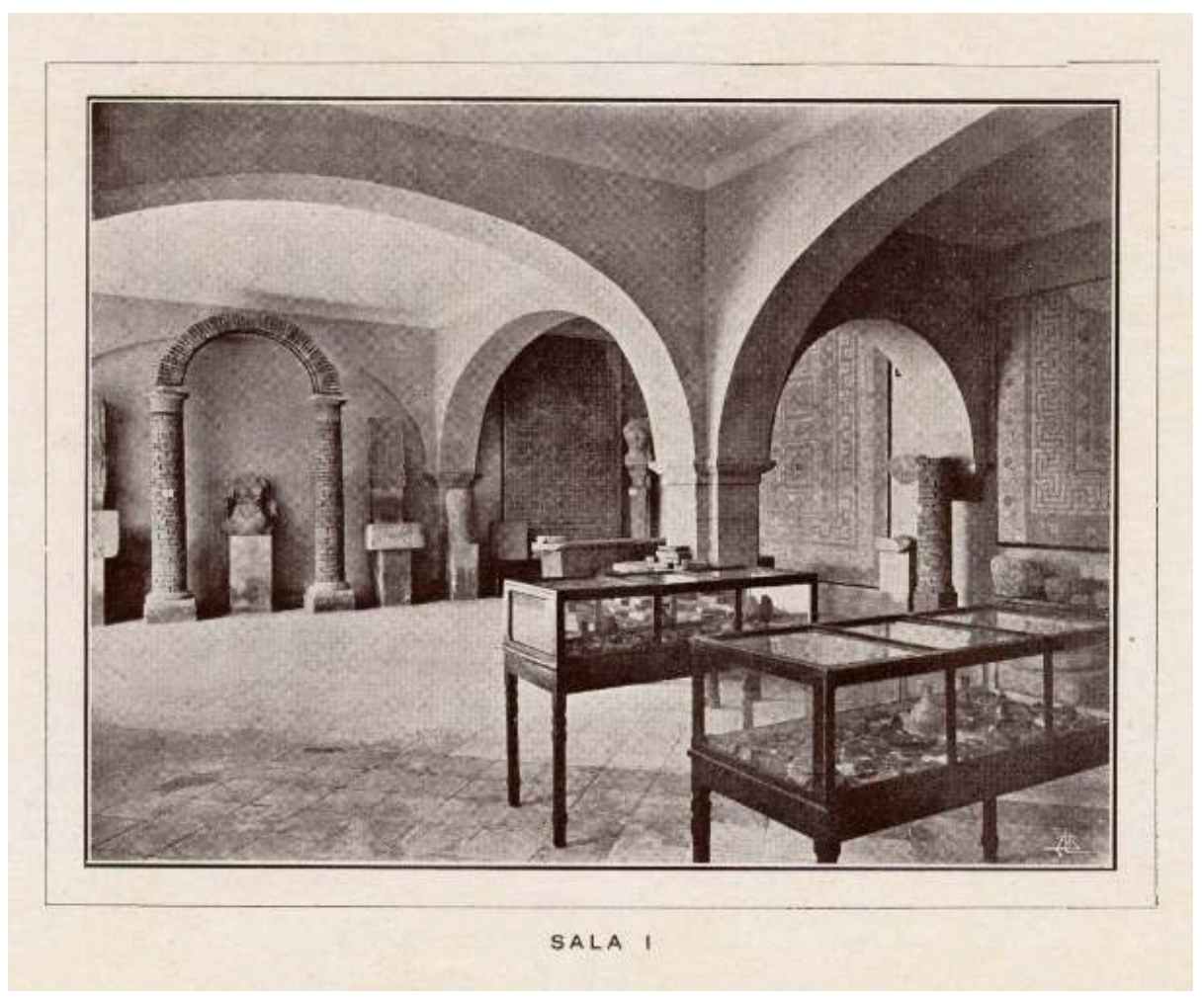

Fig. 3 - Galeria Romana do Museu Machado de Castro, onde se encontravam expostos os elementos arqueológicos exumados no oppidum de Conímbriga. 1914-1916.

(c) Arquivo Museu Nacional de Machado de Castro. Autor não identificado

Parte também de Vergílio Correia, na sua vertente menos conhecida de etnógrafo, uma reflexão sobre a missão dos museus regionais, em que, à época (1930), pretendeu incluir o Museu Machado de Castro. Numa antecipação de um modus operandi museológico característico do Estado Novo, o referido autor salientou que, para se constituir como "espelho de uma região", um museu com tais características deveria assentar na clássica tríade de coleções assentes na arqueologia, arte e etnografia, sendo esta última enaltecida como "um dos maiores atrativos":

Nem se compreende quase um museu regional sem uma vasta representação dos utensílios e artefactos da vida rural [...] utiliza, os quais creou e conserva, muitas vezes em estado de pureza originária. A vida popular de há pouco, ou a que perdura, deve poder reconhecer-se nessa secção em conjunto e pormenor, nos exemplares de trajos, mobiliário, trem caseiro e campestre, industrias e artes rústicas [...]. (Correia 1930, 328)

Conquanto tenha gizado uma seç̧ão etnográfica para o espaço museológico conimbricense, o seu falecimento gorou uma concretização efetiva. Os homens que se seguiram nos destinos do museu, o conservador António Nogueira Gonçalves (1944-1951) e o diretor Luís Reis Santos (1951-1967), compreenderam-no - quer em termos teóricos, quer na sua concretização prática - enquanto espaço de fruição e deleite das disciplinas ligadas às belas-artes, com destaque para os valiosos espécimes de escultóricos que remontam ao passado da famosa renascença coimbrã.

Ainda assim, a instituição participou, com o seu espólio e fator humano, nos alicerces da edificação de uma componente expositiva de índole etnográfica, revista no Museu Etnográfico de Coimbra (1954-1977). O conhecimento da história deste organismo ainda se encontra numa fase muito incipiente. Partindo do pouco que se sabe, constata-se que 
o projeto nasceu por volta de 1952, sob o patrocínio e posse da Câmara Municipal, com instalação prevista para a Torre de Almedina, mais propriamente nos antigos espaços da Escola Livre das Artes do Desenho.

41 Liderou a sua execução Manuel Chaves e Castro, acumulando tais funções, a partir de 1954, com o cargo de conservador-ajudante no Museu Machado de Castro (Anais do Município... 1981, 255). Deste espaço museológico foram selecionados um número significativo de objetos de características etnográficas, com a particularidade de muitos terem vindo do extinto Museu Municipal de Arte e Indústrias, através da incorporação, após a sua extinção, no Museu do Instituto de Coimbra, chegando assim ao Museu Machado de Castro (AMNMC, CE, 1953).

Seguindo as referências dadas pela imprensa regional, almejava-se que o novo Museu Etnográfico de Coimbra fosse um espelho do povo das Beiras, que refletisse o seu modus vivendi et operandi nas seguintes áreas: a habitação, o mobiliário e utensílios domésticos; a religiosidade popular, a ida a santuários e respetivos objetos de pagamento de promessas; a medicina popular e as mezinhas dos curandeiros; o vestuário típico; os utensílios de caça e de pesca; as alfaias agrícolas; as peças e técnicas artesanais; os divertimentos da vida quotidiana (festas, romarias, jogos tradicionais e brinquedos); as superstições e a literatura popular; e as diferentes indústrias artísticas (ferro, cerâmica, mobiliário, etc.) (“Secção (A) Etnográfica...” 1954, 1 e 5).

A inauguração deste museu ocorreu no dia 28 de maio de 1954, registando-se, já em 1961, a pretensão de incluir, no discurso expositivo do primeiro andar, uma seleção de obras dos artistas de Coimbra - para o qual o Museu Machado de Castro foi chamado a contribuir -, com destaque especial para o mestre António Augusto Gonçalves e a Escola Livre das Artes do Desenho, invocando, deste modo, a memória histórica do recinto (“Museu da Torre..." 1961, 7).

\section{VI - Peractio}

Do que atrás foi referido, saliente-se, à guisa de súmula, que a fundação do Museu Machado de Castro deverá ser encarada como um ponto de confluência das realizações museológicas ocorridas em Oitocentos na cidade do Mondego, ao nascer com uma missão específica, assente numa museologia para o desenvolvimento das artes industriais - em tudo coerente com um seu antepassado, o Museu Municipal de Arte e Indústrias -, recebendo ainda, na íntegra, o acervo do Museu do Instituto de Coimbra e a anexação do Tesouro da Sé, fruto, este último, da vaga laicizante que a Primeira República então preconizou (fig. 4). 


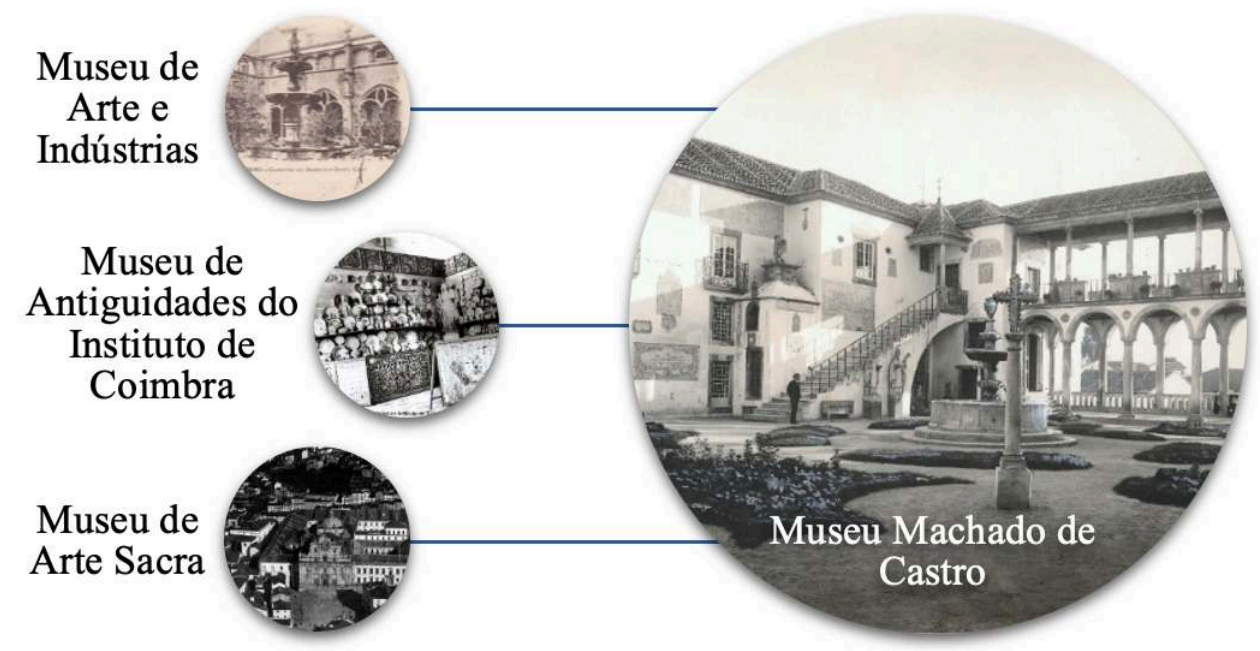

Fig. 4 - Ascendentes museológicos do Museu Machado de Castro

Composição de Duarte Manuel Freitas a partir de fotografia de autores não identificados do Arquivo Museu Nacional de Machado de Castro (c)

Feito à imagem e semelhança do seu principal ideólogo e instituidor (António Augusto Gonçalves), criou-se um espaço expositivo, sito num palácio episcopal desamortizado para o efeito, onde a identidade fundacional - assente na convergência, em modo comparativo, entre o espólio antigo e o artefacto moderno - pouco vingou, sendo ultrapassada pela força das suas coleções no âmbito das belas-artes, e pela visível decadência das agremiações que poderiam usufruir dos seus ensinamentos, como a Escola Livre das Artes do Desenho.

Novos homens trouxeram outros consolados, instituindo diferentes missões de acordo com as circunstâncias em que (académica e artisticamente) foram "criados". O Museu Machado de Castro contribuiu diretamente para a génese de outros espaços museológicos, a partir da transferência do acervo provindo do oppidum de Condeixa-aVelha para o estabelecimento do Museu Monográfico de Conímbriga - uma instituição que teve em Vergílio Correia o seu ideólogo inicial -, bem como a passagem do espólio, o know how e parte da sua história identitária para a experiência vivida no Museu Etnográfico de Coimbra (fig. 5). 


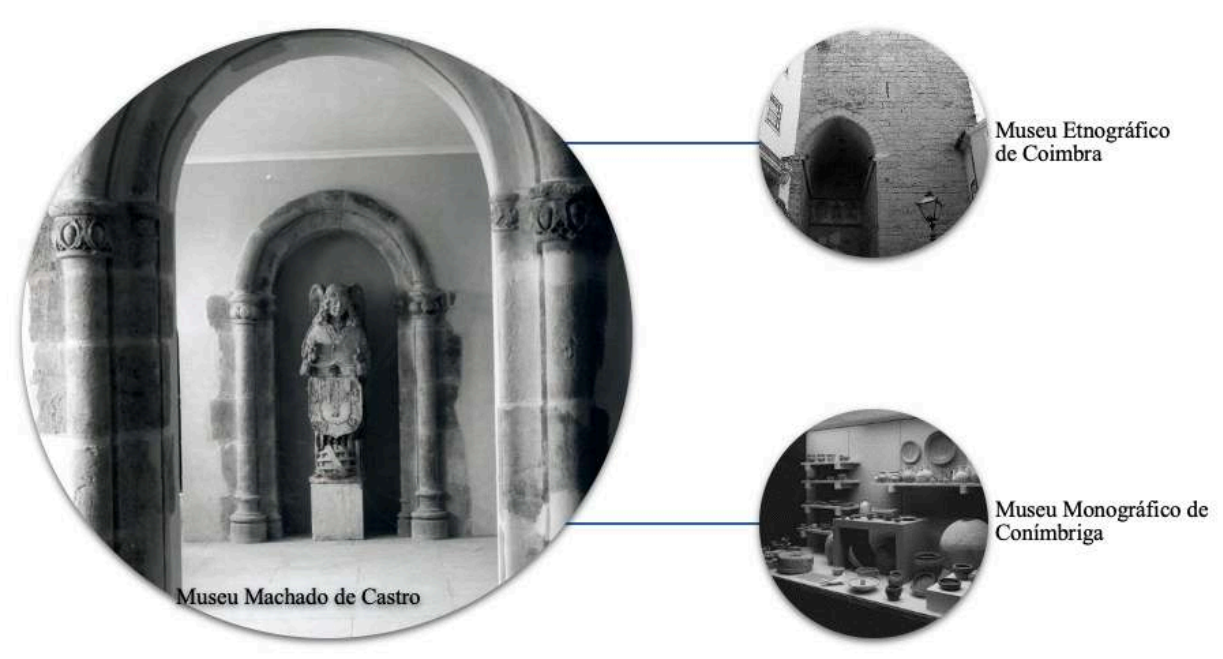

Fig. 5 - Contribuição do Museu Machado de Castro para a génese de outros espaços museológicos do distrito de Coimbra

Composição de Duarte Manuel Freitas a partir de fotografia de autores não identificados do Arquivo Museu Nacional de Machado de Castro (c)

Os casos expostos no presente artigo demonstram, com clareza, que a realidade museológica não se apresenta estática. Antes diríamos, parafraseando Galieu Galilei, "Eppur si muove", fruto: das idiossincrasias do tempo e dos contextos políticos/ ideológicos; do fator humano instituidor e da substituição deste por outros Homens com novas missões, da especificidade das coleções em exposição ou das que se encontram em reserva, com "força"/qualidade suficiente para impulsionar novos contextos expositivos.

\section{BIBLIOGRAFIA}

“Museu da Torre de Almedina." 1961. Diário de Coimbra, 10325, 31-1-1961, 7.

“Secção (A) Etnográfica e Etnológica.” 1954. Diário de Coimbra, 7884, 5-3-1954, 1 e 5.

A. 1896. "Bagatellas." Resistencia 119. 9-4-1896, 1-2.

Almeida, Lourenço Chaves de. 2007. Memórias de um Ferreiro. Coimbra: Imprensa da Universidade. Anais do Município de Coimbra (1940-1959). 1981. Coimbra: Biblioteca Municipal.

Araújo, Norberto. 1921. “Professor e Apóstolo.” Diário de Lisboa, 22-07-1921.

Arquivo do Museu Nacional Machado de Castro (AMNMC). 1952. Correspondência Expedida (CE). Carta enviada à Direção do Ensino Superior e Belas Artes. 27-1-1952.

Arquivo do Museu Nacional Machado de Castro (AMNMC). 1953. Correspondência Expedida (CE). Carta enviada à Câmara Municipal de Coimbra. 9-7-1953. 
Arquivo do Museu Nacional Machado de Castro (AMNMC). 1962. Correspondência Recebida (CR). Carta do Museu Monográfico de Conímbriga. 19-11-1962.

Biblioteca Municipal de Coimbra (BMC). 1887. Espólio Particular de António Augusto Gonçalves. Pasta B-2, Museu Municipal d'Arte e Industrias de Coimbra.

Biblioteca Municipal de Coimbra (BMC). 1910. Espólio Particular de António Augusto Gonçalves. Pasta C-2, Ao Governo da Republica, 30-12-1910.

Catalogo dos Objectos Existentes no Museu de Archeologia do Instituto de Coimbra a cargo da Secção de Archeologia do mesmo Instituto (1873-1877). 1887. Coimbra: Imprensa Litteraria.

Catalogo dos Objectos Existentes no Museu de Archeologia do Instituto de Coimbra a cargo da secção de Archeologia do mesmo Instituto, Suplemento 1.ํ (1877-1883). 1883. Coimbra: Imprensa da Universidade.

Coelho, Filipe Manuel Martins. 2016. "O Sítio Arqueológico de Conimbriga. Proposta de um Novo Museu.” Dissertação de mestrado em Arquitetura, Universidade de Coimbra.

Correia, Vergílio Correia. 1930. “Da Importância dos Museus Regionais.” Biblos VI, 318-328.

Correia, Vergílio. 1935. “Arte e Arqueologia. Como se faz um Museu.” Diário de Coimbra, 1689, 7-5-1935.

Correia, Vergílio. 1936. "Conimbriga. A Mais Importante Cidade Romana do Centro de Portugal." Diário de Coimbra, 1902, 25-05-1936.

Correia, Vergílio. 1940a. “Museus Regionais.” Diário de Coimbra, 3202, 12-02-1940.

Correia, Vergílio. 1940b. “Um Museu em Conimbriga.” Diário de Coimbra, 3190, 29-1-1940.

Correia, Vergílio. 1941. Santos Rocha Fundador dum Museu. Figueira da Foz: Esc. Gráfica.

Decreto com força de Lei de 20-04-1911. Diario do Governo, 92, 21-04-1911.

Decreto de 26-05-1911. Diario do Governo, 124, 29-05-1911.

Estatutos da Eschola Livre das Artes do Desenho. Provisoriamente Adoptados em Assembleia Geral de 25 de Outubro de 1880. 1880. Coimbra, Tygraphia M. C. da Silva.

Freitas, Duarte Manuel, e Emília Ferreira. “Simões, Augusto Filipe.” In Dicionário Quem é Quem na Museologia Portuguesa, coord. Emília Ferreira, Joana d'Oliva Monteiro e Raquel Henriques da Silva, 295-297. Lisboa: Instituto de História da Arte da Faculdade de Ciências Sociais e Humanas da Universidade Nova de Lisboa.

Freitas, Duarte Manuel. 2016. Museu Machado de Castro: Memorial de um Complexo Arquitectónico Enquanto Espaço Museológico: (1911-1965). Vol. 5. Coleção Estudos de Museus. Casal de Cambra: Caleidoscópio e Direção-Geral de Património Cultural.

Freitas, Duarte Manuel. 2019a. “Correia, Vergílio.” In Dicionário Quem é Quem na Museologia Portuguesa, coord. Emília Ferreira, Joana d'oliva Monteiro e Raquel Henriques da Silva, 82-84. Lisboa: Instituto de História da Arte da Faculdade de Ciências Sociais e Humanas da Universidade Nova de Lisboa.

Freitas, Duarte Manuel. 2019b. “Gonçalves, António Nogueira.” In Dicionário Quem é Quem na Museologia Portuguesa, coord. Emília Ferreira, Joana d'Oliva Monteiro e Raquel Henriques da Silva, 140-142. Lisboa: Instituto de História da Arte da Faculdade de Ciências Sociais e Humanas da Universidade Nova de Lisboa.

Freitas, Duarte Manuel. 2019c. “Santos, Luís Reis.” In Dicionário Quem é Quem na Museologia Portuguesa, coord. Emília Ferreira, Joana d'oliva Monteiro e Raquel Henriques da Silva, 273-275. 
Lisboa: Instituto de História da Arte da Faculdade de Ciências Sociais e Humanas da Universidade Nova de Lisboa.

Gomes, Marques. 1914. “Tesouro da Sé de Coimbra II.” Gazeta de Coimbra, 308, 4-9-1914.

Gonçalves, A. Augusto, e Eugenio de Castro. 1911. Noticia Historica e Descriptiva dos Principaes Objectos de Ourivesaria Existentes no Thesoiro da Sé de Coimbra. Coimbra: Imprensa Academica. Gonçalves, António Augusto. 1921. Monitoria Dirigida aos Srs, Ministros, Deputados e Senadores ou quem suas veses fisér. Acerca do Museu Machado de Castro de Coimbra, Coimbra, Tip. d' o Despertar.

Gonçalves, António Augusto. 1929. Enumeração das Obras Preparativas para a Instalação do Museu Machado de Castro. Coimbra: Tip. d' O Despertar.

Gonçalves, António Nogueira. 1971. “Evocação da Obra do Doutor Vergílio Correia.” In II Congresso Nacional de Arqueologia, 35-38. Coimbra: Oficinas da Gráfica de Coimbra.

Gouveia, Henrique Coutinho. 1979. "Museus de Coimbra. Da I Exposição Distrital à Organização do Museu Machado de Castro." Publicações do Museu Nacional da Ciência e da Técnica 9: 21-47.

Madahil, A. G. da Rocha. 1946. "Tentativa de Bibliografia de Mestre António Augusto Gonçalves.” In António Augusto Gonçalves. Homenagem do Instituto de Coimbra, 73-102. Coimbra: Coimbra Editora.

Museu de Antiguidades do Instituto de Coimbra. Notas. 1911. Coimbra: Typ. Auxiliar d'Escriptorio.

Officio do Bispo de Coimbra ao Ex.mo presidente do Governo Provisório da Republica. Ácerca do Thesoiro da Sé da mesma cidade. 1911. Coimbra: Imprensa Academica.

Remédios, Mendes dos. 1927. "O Grande Mestre António Augusto Gonçalves." Ilustração Moderna 16: 370-376.

Torga, Miguel. 1999. Diário. Entrada “Conímbriga, 13 de Junho de 1944.” 2.. edição Integral. Vol. 1. Lisboa: D. Quixote.

Vasconcelos, António de. 1932. “António Augusto Gonçalves.” Ilustração Moderna 58: 508-511.

Zebedeu. 1917. “Banalidades.” Resistencia 157, 7-10-1917, 1.

\section{NOTAS}

1. O presente artigo constitui, em parte, uma reflexão em torno de temáticas por nós já exploradas na obra Museu Machado de Castro. Memorial de um Complexo Arquitetónico Enquanto Espaço Museológico (1911-1965) (Freitas 2016). Pretendeu-se, de igual modo, trazer novos contributos para a compreensão da evolução histórica da museologia conimbricense, apresentando fontes inéditas, do ponto de vista da sua aplicação num discurso historiográfico. 


\section{RESUMOS}

No presente estudo almejamos não só delinear o "passado genético" do Museu Nacional de Machado de Castro (Coimbra), fundado em 1911, como também listar o seu contributo, a vários níveis, na criação de outros espaços museológicos no distrito onde se insere. A partir da análise das fontes coligidas (escritas e icononímicas) estabeleceu-se uma estrutura discursiva que se inicia com uma breve reflexão sobre o nascimento e o perecimento dos fenómenos museológicos (I - In Principio), seguindo-se a compreensão do fator humano instituidor (II - Ecce homo), com destaque para António Augusto Gonçalves (1848-1932), fundador e primeiro diretor do museu, sendo uma das figuras notáveis no meio conimbricense das artes e da proteção do património. No momento seguinte (III - Avorum), procurar-se-á as origens remotas da instituição, a partir do estudo de três organizações museológicas tardo-oitocentistas da cidade (Museu Municipal de Arte e Indústrias, Museu do Instituto de Coimbra e o Tesouro da Sé), recebendo delas o espólio, os vetores missionais e o know-how. Examina-se, em seguida, o ato fundador do MNMC (IV Nativitate), marcado por um novo contexto sociopolítico definido pela então jovem República Portuguesa e pelas conceções museológicas firmadas pelo seu instituidor. A contribuição do museu estatal conimbricense na criação e manutenção de dois novos espaços museológicos (Museu Monográfico de Conímbriga e o Museu Etnográfico de Coimbra) será, de igual modo, evidenciada (V - Semina), apresentando-se já nas considerações finais (VI - Peractio), para além da habitual súmula, uma árvore genealógica do objeto de estudo.

This study aims not only to outline the "genetic past" of Museu Nacional de Machado de Castro (Coimbra), founded in 1911, but also to list its contribution, at various levels, in the creation of other museum spaces within the district it operates. Based on the analysis of the collected sources (written and iconographic), a discursive structure was established, which begins with a brief reflection on the birth and perishing of the museological phenomena (I - In Principio), followed by an understanding of the personalities involved (II - Ecce homo), with special emphasis on its founder and the first director - António Augusto Gonçalves (1848-1932) - without neglecting his role as an artist and heritage's protector. Subsequently, we will look for the institution's remote origins, from the study of three late 19th-century city museums (Museu Municipal de Arte e Indústrias; Museu do Instituto de Coimbra and the Tesouro da Sé), receiving the estate, the missional vectors and the know-how from them (III - Avorum). Then, the founding act of the MNMC (IV - Nativitate) is examined, emphasizing the new socio-political context defined by the then young Portuguese Republic and by the museological concepts signed by its founder. The contribution of Coimbra's state museum in the creation and maintenance of two new museological spaces (Museu Monográfico de Conímbriga and the Museu Etnográfico de Coimbra) will also be demonstrated (V - Semina), presenting itself in the final considerations (VI - Peractio), in addition to the usual summary, a family tree of the object of study.

\section{ÍNDICE}

Keywords: museology history, Museu Nacional de Machado de Castro, António Augusto Gonçalves, museums history, biography

Palavras-chave: história da museologia, Museu Nacional de Machado de Castro, António Augusto Gonçalves, história dos museus, biografia 


\section{AUTOR}

\section{DUARTE MANUEL FREITAS}

É natural de Câmara de Lobos (Ilha da Madeira). Obteve o doutoramento em História (regime préBolonha), na especialidade de Museologia e Património Cultural, pela Universidade de Coimbra (2015). Na atualidade, é professor auxiliar do Departamento de História, Artes e Humanidades da Universidade Autónoma de Lisboa. Colabora com diferentes unidades de investigação, sendo membro integrado do Centro de História da Sociedade e da Cultura da Universidade de Coimbra e do Centro de Investigação em Ciências Históricas da Universidade Autónoma. Publicou vários estudos científicos e manuais nas áreas de investigação da Didática da História, da Museologia Histórica e da História das Empresas.

Centro de Investigação em Ciências Históricas, Universidade Autónoma de Lisboa, Rua de Santa Marta, n.ำ 47 - 5.ำ andar, 1169-023 Lisboa, Portugal, dfreitas@autonoma.pt 